\title{
Financial Management Practices and Financial Performance of Service Companies in Somalia
}

\author{
Ali Yassin Sheikh Ali* \\ Faculty of Economics, SIMAD University \\ Adan Osman Isak \\ Master of Finance, Postgraduate Center, UNIVERSITY OF SOMALIA
}

\begin{abstract}
The objective of this study was to witness the effect of the financial management practice on the financial performance services companies in Somalia. This study viewed the effect of financial management practice of all the mechanisms of financial management those were specifically; working capital, investment decision and financial decision of the services companies in the Mogadishu area. The study employed explanatory and descriptive research design. A sample of 145 respondents was selected using the stratified sampling technique.. The data collected through a cross sectional questionnaire.The findings discovered that Working capital, investment decision, are significant determinants of financial performance of the services companies in Somalia. The findings indicated that the most important variable in the model was investment decision $(\beta=0.544)$. This was followed by working capital management $(\beta=0.419)$, while financial decisions were $(\beta=-0.010$.), these showed rejected. The study, therefore, recommends that services companies in Mogadishu needed to have Working capital management policy and investment decision policy which were impacted positively on the overall financial performance.
\end{abstract}

Keywords: Working capital management, Investment decision and financial decision and financial performance. DOI: $10.7176 /$ RJFA/10-4-07

\section{INTRODUCTION}

Financial management framework comprises the processes, systems, internal controls and practices relating to the way the department manages its revenues, expenses, assets, liabilities, and contingencies. It also includes its policies for managing risk and monitoring its financial and operational performance, including budget performance and reporting on these functions, both internally and externally.

Ideally, business companies are expected to grow and expand by transitioning from one step to the next; from small businesses to the corporate which have many employees. Regardless of the high number of companies born, their death rate remains very high even in developed countries. Suitable financial management practice also plays an important role in helping service companies gain access to capital which is essential for business growth and profitability. A good financial management practice system should ensure the succeeding quantitative characteristics are met: understandability, significance, materiality, reliability, and substance over form, carefulness, completeness, comparability, suitability and a equilibrium between benefit and cost yet they continue to lack in most private service companies (DEMBA 2013).

This study therefore is designed to create how the financial management practices influences financial performance. Another side the study from east Africa argued that, a good micro and small enterprise financial management system should ensure the following qualitative features are met: understandability, significance, materiality, consistency, and element over form, practicality, completeness, comparability, appropriateness and an equilibrium between benefit and cost yet they continue to the absence in most micro and small enterprise. This study, therefore, is planned to present how the financial management practices by MSEs affect their performance, business development and growing (Town et al. 2017).

Therefore, lack of financial management practices in service companies for decision making and lack of practical skills is as a vast amount barrier to growing service companies as is the powerlessness to access their performances. Some service companies in Somalia used accounting as they to manage the daily activities of their businesses, but it is irrelevant to maintain financial management practices and financial performance.

None of the reviewed studies have sought to explain how financial management practice with working capital management, investment decisions, and financing decisions impacted the financial performance of service Companies in Mogadishu Somalia. Nothing of these domestic and international studies have motivated on the effects of financial management practices on financial performance in service companies Mogadishu Somalia. This is the gap that the study would investigate and solving that problem.

\subsection{Significance of the study}

This study will be significant for services companies to get them the concept that related the effect of financial management practices on financial performance. Strategy creators were using the information gained from this 
study for their design, formulation regarding financial management practice of service companies in Mogadishu Somalia. This relationship showed the significance of financial management practice as a sponsor of the financial performance of services companies. This research provides academic support to the effect of financial management practices in services companies in Mogadishu Somalia. Future investigators would, therefore, use the findings of this study to further advances and future research projects that were found this study significant. This study would benefit for the opportunity, researchers looked for literature about the influence of financial management practice on financial performance, who is interested in carrying out for additional study in this playing field.

\section{LITERATURE REVIEW}

Financial management practices can be explained using various theories. Extra, research findings on how various features of financial management affect a firm's financial performance differ. This chapter discusses the pecking order theory on financial management and reviews literature on how working capital management practices, investment decisions and financing decisions, and analysis effect on the financial performance of a firm. The chapter also identifies the research gap.

The study presented that measured individually; there is a definite connection between working capital management, investment decisions; financial decisions and financial performance. Also, the study indicated that the collective effect of financial management practices in working capital management, investment managing, and financial managing business decision has a moderate positive relationship between financial management practices and financial performance (Njagi and Kariuki 2017).

Another study in Kenya examined the effect of internal corporate social responsibility on firm financial performance, evidence from Kenya commercial bank. Social interchange theory directed the study. Researcher to complete his research was used employee welfare, equity, benefit and workforce diversity as independent variables; the firm financial performance was used in the dependent variable. He used instrumental stratified and a random sampling technique with quantitative. Also, he was using the graphics research design to find the cause-effect relationship and selected a sample size of 165. From the study findings, there is enough evidence to conclude that employee welfare is associated with higher financial performance. Financial sustainability will increase with an increase in employee welfare.

The study also provides some preliminary evidence that equity plays a vital role in improving business performance. Specifically, talent is tapped from the workforce, and this leads to a considerable increase in financial performance. (Based et al. 2016).

The research in Kenya investigated Working Capital Management Practices and Financial Performance of Tea Processing.

The principal object the objective of this study was to determine the effect of working capital management practices on the financial performance of the tea processing firms in Kenya. The research was used descriptive research design with adopted Stratified random sampling method, and quantitative analysis methods with selfadministration techniques were used. Two testing hypotheses were used Inventory management practices; Payables management practices are used as independent variables while the financial performance of Tea processing firms uses dependent variables.

The study found that tea processing firms have conservative an inventory and payment management policies to control the firms in managing their inventory. The Pearson correlation and ANOVA results showed that inventory management has a significant negative relationship with the financial performance of tea processing firms. The subject, consequently, mentions tea processing firms to ensure the entire amount of days taken before inventories are sold is reduced to amend the returns of the firms. The more extended the period was chosen to settle accounts payables, therefore, increased profitability of a firm (Kiprotich 2013).

Nothing of enough the reviewed studies has sought to explain how financial management practices of financial performance, those contain working capital management, investment decisions, and financing decisions affect the financial performance of services companies in Mogadishu. This is the gap that this research was investigate.

\section{RESEARCH MODEL}

The figure below offerings the conceptual framework guide this research. The research has three independent variables that were used to measure financial management practice. These three variables are working capital management, business decisions, and investment decisions. The dependent variable is financial performance measured by sales volume, asset growth, and profit. The intervening variables include management skills, ownership, business objectives, business risk environment and financial market development. The management skills will determine how the independent variables affect financial performance. If there are useful management skills and methods, the independent variables will positively lead to improved financial performance (Addo 2017).

The literature review theories show that Working Capital Management, investment decisions, and financing decision analysis as a variety of financial management are thoroughly related to the financial performance of a 
firm. However, the findings of the study offered that measured individually; there is a positive relationship between working capital management; investment decisions; financial decisions and financial performance. Also, the study showed that the collective effect of financial management practices in working capital management, investment decision, a business decision has a reasonable positive relationship between financial management practices and financial performance. (Njagi and Kariuki 2017).

The study in Ghana investigated the relationship between Financial Management Practices by Small and Micro Enterprise Owners in Ghana - Evidence from the Central Region. The findings show how disorganized, possibly carelessly, the business owners have financially managed their respective enterprises. Indeed, only less than twenty percent of the respondents understand the meaning of financial management, and, nevertheless, of the business segment differences, the most majority of the respondents had inappropriate that maintaining correct financial records was all that financial management meant (Kwaning, Director, and Assah 2015). This is the gap that the researcher was investigated.

Independent Variables

Dependent V. Variables

Financial Managemnet

1. Working Capital Management

2. Investment Decisions

3. Financial Decisions

Financial Performance

- Sales Volumes

- Assets growth

- Profit

Figure 1: Conceptual framework

\section{METHODOLOGY}

\subsection{Research Design}

This research was used explanatory \& descriptive research design method for analyzing demographic and another dimension. Also further to explain variables we used analytical research methods. This method is similar to the method used by (Kabethi 2013), Who conducted financial management practice on business performance that research focused on SMEs. A descriptive research design describes or defines a subject, through creating a profile of a group of problems, people, or events, through the collection of data, the tabulation of the frequencies on research variables and the analysis of their collaboration.

A cross-sectional description survey research design was adopted for this study because the Cross-sectional is cost and time effective.

This research methodology was appropriate for this study based on the fact that the researcher intended to collect detailed and current information that would enable identifying and describing the current situation concerning financial management on performance in services companies in Mogadishu Somalia. The survey allowed a reasonable analysis of the variation of financial management for large or small services Companies in Mogadishu region.

\subsection{Measurement of variables}

Effect of financial management practice on financial performance tendencies toward Working capital, investment decision, financial decision, financial performances were measured using a $29^{\text {th }}$ items, five point interval scale type scale ranging from strong disagreement with questions to, disagreement, with questions natural and strongly agree with questions agree (Ali and Ali 2014). Each dimension of financial management practice, working capital, investment decision and financial decision were describing three questions financial performances are measured asset growing, profit growing and businesses growing by using five point interval scale type scale ranging from strongly disagree, disagree which have questions, neutral with questions and strongly agree with questions and agree with questions.

\subsection{Sample Size}

The target populations of this study were services companies those include electrics, telecommunications, Banks, and universities in Mogadishu Somalia and number of populations are unknown. Therefore, the researcher was used literature review both population and sample. Since there are vast numbers of companies that as time and costs are cannot overcome, the researcher takes Some of Managers and employees who are working in the department of financial management services companies in Mogadishu Somalia. Because of required relevant information that can be leading the reliability of this study, researchers were used managers and employees who know to account, and financial management as target populations of each institution is selected. Researchers 
selected 130 employees who are included managers and employees; those are working department of finance.

The same way the researcher is collecting managers and employees of the Department of Finance for each company are selected; our primary choice is the managers, employees or whether the owner is, those are experienced with the Financial Management. Also, the researcher considered all the staff of line managers who have requirements in finance or accounting for each company.

\subsection{Research Modeling}

The current study begins the causal relationship between variables, so researcher attempting clear research design to highlighting on studying a condition or a problem to describe the relationships between Working capital management and financial performance, influences of Investment management, and financial performance, influences of financing, and financial performance.

This study uses the descriptive and inferential statistical methods was used to analyze the data. Multivariate regression Model based on Cross-sectional collected data from the respondent the questionnaire which related Working capital Management, investment, financial decisions and financial performance criteria.

To complement the regression analysis, correlation analysis was passing out to investigate the relationship between working capital management, financial management, investment management, and financial performance. Analysis of consequence was approving out for all variables using t-test at a $95 \%$ level of significance and $5 \%$ of standard error. To study the relationship between these variables, Pearson correlation coefficients were calculated,(DEMBA 2013).

\subsection{Data Collecting and Instruments}

Research Instrument is self-administered questionnaires were used to collect data from the owners or finance managers and employees in working finance department of the identified services companies. Also, the researcher is using a cross-sectional questionnaire. The survey used mainly the closed-ended questions with a few open-ended questions.

The questionnaire was divided into five sections. Section A captures the demographic information about the respondent. Section B captures information concerning working capital management. Section C focuses on investment decisions; Section D focuses on financing decisions. Section E captures financial performance, (Addo 2017).

\section{DATA ANALYSIS}

\subsection{Demographic Information}

The study required to start the all-purpose information of the respondents containing their gender, age, marital status, level of education and work experience, the title of respondents, the age of the companies, the position held, industry position, size of the company and annual sales turnover. $76 \%$ of respondents were male, $24 \%$ of respondents were females. The study set up that $48 \%$ of respondents were in the range of $25-35$ years. The $40 \%$ of the respondents were an assortment of 36-45 years, and $12 \%$ of the respondents were groups of 46 years and above.

On the marital status, $75 \%$ of the respondents were married, $24 \%$ of the respondents were single, while $1 \%$ of the plaintiff had divorced. The findings are presented in the table below. The study also wanted to establish the respondents' uppermost level of education. According to the results, the majority of the respondents, 59\% had a Bachelor degree, $19 \%$ had a Master degree, $13 \%$ had a diploma, and 5\% hold the Ph.D. degree while 4\% of the respondents had a certificate.

The study investigated work experiences of respondents the researcher sought that $38 \%$ of a defendant were 6-10 years, $32 \%$ of plaintiff were $1-5$ years while $30 \%$ of respondents were 10 and above years as the findings represented below a table. 


\section{Demographic table 1:}

\begin{tabular}{llll}
\hline & Gender & & \\
& Category & Frequency & Percentage \\
1 & Male & 99 & $76 \%$ \\
2 & Female & 31 & $24 \%$ \\
& Total & 130 & $100 \%$ \\
& Age & & \\
\hline 1 & Category & Frequency & Percentage \\
& $25-35$ & 63 & $48 \%$ \\
2 & $36-45$ & 52 & $40 \%$ \\
3 & 46 Above & 15 & $12 \%$ \\
& Total & 130 & $100 \%$ \\
& Category & Single & Frequency \\
2 & Married & 31 & $24 \%$ \\
3 & Divorce & 98 & $75 \%$ \\
& Total & 1 & $1 \%$ \\
\hline
\end{tabular}

\section{Educational Level}

$\begin{array}{lll}\text { Category } & \text { Frequency } & \text { Percentage } \\ \text { Secondary } & 5 & 4 \% \\ \text { Diploma } & 17 & 13 \% \\ \text { Bachelor } & 77 & 59 \% \\ \text { Master } & 24 & 19 \% \\ \text { PhD } & 7 & 5 \% \\ \text { Total } & 130 & 100 \%\end{array}$

\begin{tabular}{lll}
\hline Work Experiences & & \\
$\quad$ Category & Frequency & Percentage \\
1-5 years & 42 & $33.2 \%$ \\
6-10 years & 49 & $37.7 \%$ \\
10 years and above & 39 & $30 \%$ \\
\hline
\end{tabular}

The study indicated that the most type of businesses $88 \%$ of the respondents were the partnership, $8 \%$ of the respondents were Single Proprietor, while $6 \%$ limited liability companies. The side of the titles of the companies $58 \%$ of the respondents were employees and $36 \%$ were Managers, while $6 \%$ were owner Managers.

The side of the Size of the Companies showed $71 \%$ of plaintiffs were large Companies which are higher than 250 employees, $26 \%$ respondent was the medium (50-249), while 3\% were Small (10-100). The study investigated firms ages that $58 \%$ of respondents were more than above ten years, $23 \%$ respondent was less than $1-5$ years, while $19 \%$ of the respondents were more than $6-10$ years.

The researcher investigated the position held by the respondents, $88 \%$ of the respondents were financial personnel in the companies, and $6 \%$ of the respondents were the public relation, while $6 \%$ of the respondents were marketing. The study investigated industries, levels $96 \%$ of the respondents were Services companies, $4 \%$ of the respondents including the financial institution and trading

The study examined annual sales turnover that $62 \%$ of the respondents showed annual sales turnover were more significant than 3 Million, 23\% of the respondent were 1.5 - 2 Million, while $14 \%$ were included 150,0001 million. 
Table 2: Companies Information

\begin{tabular}{|c|c|c|}
\hline \multicolumn{3}{|c|}{ Type of Business } \\
\hline Category & Frequency & Percentage \\
\hline Single Proprietor & 11 & $8 \%$ \\
\hline Partnership & 112 & $86 \%$ \\
\hline Limited Liability Company & 7 & $6 \%$ \\
\hline Total & 130 & $100 \%$ \\
\hline \multicolumn{3}{|l|}{ Title } \\
\hline Category & Frequency & Percentage \\
\hline Owner Manager & 7 & $6 \%$ \\
\hline Manager & 47 & $36 \%$ \\
\hline Employee & 76 & $58 \%$ \\
\hline Total & 130 & $100 \%$ \\
\hline \multicolumn{3}{|l|}{ Size of the Company } \\
\hline Category & Frequency & Percentage \\
\hline Small $10-49$ & 4 & $3 \%$ \\
\hline Medium 50-249 & 33 & $26 \%$ \\
\hline Large 250 and above & 93 & $71 \%$ \\
\hline Total & 130 & $100 \%$ \\
\hline \multicolumn{3}{|l|}{ Table 4.4 Continue } \\
\hline \multicolumn{3}{|l|}{ Firm Age } \\
\hline Category Percentage & Frequency & Percentage \\
\hline Less than 5 Years & 30 & $23 \%$ \\
\hline $6-10$ years & 25 & $19 \%$ \\
\hline More than 10 years & 75 & $58 \%$ \\
\hline Total & 130 & $100 \%$ \\
\hline \multicolumn{3}{|l|}{ Position } \\
\hline Category & Frequency & Percentage \\
\hline Public relation Personnel & 8 & $6 \%$ \\
\hline Financial Personnel & 115 & $88 \%$ \\
\hline Marketing Personnel & 6 & $4 \%$ \\
\hline Operations Division & 2 & $2 \%$ \\
\hline Total & 130 & 100.0 \\
\hline \multicolumn{3}{|l|}{ Industry } \\
\hline Category & Frequency & Percentage \\
\hline Trading & 4 & $3 \%$ \\
\hline Service & 125 & $96 \%$ \\
\hline Financial Institution & 1 & $1 \%$ \\
\hline Total & 130 & 100.0 \\
\hline \multicolumn{3}{|c|}{ Annual sales turnover of the Companies } \\
\hline Category & Frequency & Percentage \\
\hline 150 th- $300^{\text {th }}$ & 9 & $7 \%$ \\
\hline 350th- $1 \mathrm{M}$ & 10 & $8 \%$ \\
\hline $1.5 \mathrm{M}-2 \mathrm{M}$ & 30 & $23 \%$ \\
\hline Greater than $3 \mathrm{M}$ & 81 & $62 \%$ \\
\hline Total & 130 & 100.0 \\
\hline
\end{tabular}

\subsection{Reliability analysis of all variables}

A construct combination reliability coefficient (Cronbach alpha) will use to determine reliability. The aim of this test will define whether the tools consistently measured what they were intended to measure. A Cronbach alpha of 0.6 and above, for all the constructs, will consider being adequate for this study. Another study argued that a reliability analysis would be directed to evaluate the internal contents of the items by using Cronbach's alpha. A variable is consistently and internally reliable when the alpha is 0.70 and above (Babin and Anderson n.d. 2010). However, (Bowling, 2002) proposes that an alpha of 0.50 and above is a suggestion of internal consultancy.

Table of reliability indicates that Cronbach's alpha for the working capital management scale was 0.819 , which registered accepted. The table also revealed that the items did not allow for Cronbach's alpha were removable which was (temporally cash surplus is invested in marketable securities -WC4), and (the business has a set credit policy in place- WC8), thus the question was eliminated from the scale as they dropped the reliability of the builds. The security of the second item indicated that Cronbach's Alpha for Investment Decision scale was 
0.765, which registered accepted. The table showing that the issue did not receive for Cronbach's Alpha was removed, which was (the business invests without evaluating the investment- ID6); therefore the question was eliminated from the scale as they released the reliability of the shapes. The authenticity of the third items was the financial decision that its Cronbach's Alpha scale was 0.788 which registered acceptable. Table of safety indicates that Cronbach's alpha for the financial performance scale was 0.726 which registered accepted. The table presented that the item didn't receive the Cronbach's Alpha was removed, which was FP5, and then a question was eliminated from the scale as they uncovered the reliability to build.

The maximum alpha was obtained by alpha for the working capital management scale was $0.819(\alpha=.852)$, followed by financial decision $(\alpha=.788)$ and investment decision $(\alpha=.765)$. The lowest alpha was found to belong to financial performance $(\alpha=726)$.

Table 2: Reliability report

\begin{tabular}{lllc}
\hline Variables & Cronbach's Alpha & Number of items & Number of items deleted \\
\hline Working Capital & 0.819 & 8 & 2 \\
Investment Decision & 0.765 & 9 & 1 \\
Financial Decision & 0.788 & 4 & 0 \\
Financial Performance & 0.726 & 4 & 1 \\
\hline
\end{tabular}

\subsection{CORRELATIONS ANALYSIS}

The first objective of this study is investigating the relationship between working capital and financial performances, in serving companies in Mogadishu Somalia. As you will see table 4., shows the results of a correlation analysis of the relationships among working capital, investment decision, financial decisions, and financial performance.

Hence, working capital has positive has a significant positive relationship with financial performance $(\mathrm{r}=.753 * *$ and $\mathrm{p}=.000)$. Besides, firm actively present improvements and in working capital management in services business, changes in service line moreover, firm actively current improvements and in working capital management in services business, changes in service line have been quite affected and firmly encourages development of employees ideas for business improvement then, firms with higher working capital management tend to achieve higher growth rate, employees keeping better, increasing on sales with growing market share, also gaining values of assets with always growing and better positive upcoming of the business, and promote higher profitably business year by year.

Working capital has a significant positive relationship with investment decisions $\left(\mathrm{r}=.796^{* *}\right.$ and $\left.\mathrm{P}=.000\right)$. Those items showed in the improved financial performances. Also working capital has a significant positive correlation with the financial decisions $\left(\mathrm{r}=.248^{* *}\right.$ and $\left.\mathrm{P}<.004\right)$, in this relationship between working capital and financial decision are a weak relationship. Also, the second objective of this study was to identify the relationship between Investment decisions and financial performance in services companies in Mogadishu, Somalia.

Investment decision has a positive relationship between financial Performances in services companies in Mogadishu Somalia. This means it has correlations with $(\mathrm{r}=.773 * *$ and $\mathrm{p}=0.000)$. This means services companies in Mogadishu, Somalia was more usefulness Investment that improved financial performances of each company.

The third objective was to assess how the financial decision influences financial performances in services owned companies in Mogadishu, Somalia. The correlation between financial decision and financial returns are very weak as presented the table 4.10 . It states that one level of the financial decision increases a little of financial performances too $(r=0.168 \mathrm{p}<.057)$. This correlation shows there is a weak correlation with financial decisions and financial returns; also we can say there insignificant while $\mathrm{P}<0.057$.

\begin{tabular}{llllll}
\multicolumn{1}{l}{ Table 4: Correlation Analysis } & & & \\
\hline No & Variables & 1 & 2 & 3 & 4 \\
\hline 1 & Working capital & 1 & & & \\
2 & Investment decision & $.796^{* *}$ & 1 & & \\
3 & Financial decision & $\mathbf{. 2 4 8}^{* *}$ & $.209^{*}$ & 1 & \\
4 & Financial Performance &. $\mathbf{7 5 3}^{* *}$ & $.773^{* *}$ & .168 & 1 \\
\hline
\end{tabular}

\subsection{REGRATIONS ANALYSIS}

Regression analysis was players off to examine the relationship between the variables of the study; the hypotheses were developed; the first hypothesis were indicated relationship Working capital management and financial performance $(\mathrm{H} 1)$, the regression analysis result in Table (4) indicated that working capital management has a positive and significant influence on the financial performance of services companies in working Mogadishu Somalia, $(\beta=.419, \mathrm{t}=4.318, \mathrm{p}=0.000)$. Therefore, this finding supports H1. Similarly the below table demonstrates that investment decisions have a positive and significant relationship on financial performance $(\beta=.544, \mathrm{t}=5.467$, $\mathrm{p}=0.000)$. Therefore $\mathrm{H} 2$ was accepted. Whereas financial decisions indicates Negative and insignificance influences on financial performance $(\beta=-.010 . \mathrm{T}=-.483, \mathrm{p}<.630)$ Therefore $\mathrm{H} 3$ was rejected to influences financial 
performances for services companies in Mogadishu Somalia. The independent variables were explaining 66.6\% of the changes occur on dependent variables.

The results of regression analysis suggested that working capital management, investment decision, financial decision and financial performances of managers and owners owned service companies $(\mathrm{R}=80.6 \%)$ was the best forecaster of the financial performance. This means if the managers and owners of services companies in Mogadishu, Somalia focused working capital management and invested decisions to become financial management practice, this will contribute to the financial performances of each services company. Other side, managers and owners of services companies in Mogadishu, Somalia they are not trusted for financial decision, because regressions show that.

Table 4: Regression analysis

\begin{tabular}{llllll}
\hline No & Variables & Beta & T & Sign & Remarks \\
\hline 1 & Working Capital & 0.419 & 4.318 & 0.000 & H1:Accepted \\
2 & Investment decision & 0.544 & 5.467 & 0.000 & H2:Accepted \\
3 & Financial decision & -0.010 & -0.483 & 0.630 & H3: Rejected \\
& R & $0.806^{\mathrm{a}}$ & & & \\
& R Square & 0.650 & & & \\
\hline
\end{tabular}

\section{DISCUSSION AND CONCLUSION}

This study was highpoint the significant role of basing financial management practice on the financial performance of the services industry sector in Mogadishu Somalia. The study investigated and argued that working capital management, investment decision; the best managed and practices could discover financial performance.

The results of this study confirm a significant effect of financial management practices with the positive direction of the financial performance services companies in Mogadishu Somalia. This means that the best financial management practice can improve the values of the financial performance of services companies like banks, telecommunication, universities, and electrical power, which study based on investigating, the findings confirmed, if the form of an increase in capital, trained and promoted employee, changes in financial turnover and increased profits.

An excellent application of financial management practice will be leading to increased financial performance. That explains the attainment of sound financial management practice is expected to continue expanding in the future be improved. This means that the value of training, employee, encouraged and stimulated managers the results will be the reflect through honest and moral responsibility in firm activities, therefore companies can use of the working capital management and investment decision to growing their profit and company, while employee, managers, and owner-manager confirmed there is insignificance relationship with financial decision on financial performances for all sample of services companies in Mogadishu Somalia.

Three hypotheses were analyzed grounded on the literature review, but regression analyzed showed two factors of Financial management practices well used services companies in Mogadishu Somalia. Therefore, as researcher will be testing two hypotheses only as shown in the table below. In direction to test these hypotheses, a linear compound regression analysis will show to get the best predictor.

Furthermore, the purpose of this study was to discover the role the effect of financial management practice on the financial performance of services companies in Mogadishu Somalia. Therefore, this study was to identify the influence of working capital management, on financial returns. To have a positive effect on financial performance, the study tested the correlation by using Pearson product thrust correlation. And the result obtained indicated that there is a strong positive relation

Among relationships except for financial decision, while these variations noted negative associations with financial performance. The results suggested that financial management practice has great influence on financial performance; i.e., Working capital has $(\mathrm{r}=.753 ; \mathrm{P}=0.00)$ impact on the financial performance, while investment has $\left(\mathrm{r}=.773^{* *} ; \mathrm{P}=.000\right)$ correlation with financial performance. This means if financial management practice dimensions (Working Capital, and Investment decision) are possibly managed, then their effects on financial performance (employees keep getting better, the sales business have always grown, the value of asset company has been increasing, and profits have been growing yearly, lead to achieving the financial goal and objectives. On the additional, the researchers investigated and tested the hypothesis. The first hypothesis indicated the relationship between working capital management and financial performance and found that there is a significant relationship between the variables $(\beta=0.419 ; \mathrm{T}=4.318 ; \mathrm{P}=0.000)$ therefore $\mathrm{H} 1$ was accepted. The second hypothesis showed that there is a relationship between investment decision and financial performance, as exemplify that there is a significant relationship between the variables $(\beta=0.544 ; \mathrm{T}=5.467 ; \mathrm{P}=0.000)$. As a result, the $\mathrm{H} 2$ was accepted. The third hypothesis of this research as well indicated that there is not a correlation between financial decision and financial performance, and lastly found that there is an insignificant relationship between the variables $(\beta=-0$. $010 ; \mathrm{T}=-.483 ; \mathrm{P}=0.630)$ therefore $\mathrm{H} 3$ was rejected. With the total score of the hypothesis $(\mathrm{R}$ Square $=0.650)$ which means the estimated hypothesis discussed in chapter two of our study corresponds with the real results. However, 
some researches have been supporting the current findings, these studies conducted through financial management practice on financial performance and the two of them recognized that there is a positive relationship between the variables. The results of this study support the views expressed in the survey conducted by (Njagi and Kariuki 2017), indicated that investigated financial management practice of financial performance with services companies in Mogadishu Somalia. An additional study of (DEMBA 2013) discovered relationship, financial management practice with financial performance, and the researchers found a positive relationship between the two variables except for one variable that is the financial decision and financial performance. The results of this study confirmed the views expressed by (Mwangi, Otuya, and Kamau 2014) that financial management practice subsidizes to improve financial performance and reduce mismanagement for the finance.

The significance of the finding of this research equals the results of the reviewed literature on the topic, which also explain that there are strong positive correlations between financial management practice and financial performance. As researcher previous estimated in chapter two the findings and our prediction converted the same. Opportunity research should further investigate ambiguous that affect services effect of financial management practice way, financial performance and services business sector. Such analysis may be helpful to leader financial management policy, meanwhile empathetic the associations between these immaterial are significant for reassurance value of working capital management, investment decision, financial decision, and effectiveness. Our study confirmed that ranked regression equation modeling could be used for assessing the relationship between the variables financial management practice and financial performance.

Furthermore, many similar studies in the rest of the world, as well as studies based on additional indicators of the effect of financial management practices and financial performance, confirmed the same result that study conducted. Therefore the investigation came to be familiar with those employees of professional private know small on financial pieces of the business financial performance, and this director them with the statement that their firms are financially appropriate, while there is an exit option of the opposing.

This study examined the relationship between financial management practices on financial performance among using services companies in Mogadishu. These results were supported past studies as effective financial management practice on financial performance, which are generally seen as a motivation toward well-managed assets, growing profitability; the rewarded employees keep getting better. Firm growth, at the minimum within positive situations, has been shown to be positively relationship having a positive impact on financial performance(Chen, Jung, and Chen 2011), (DEMBA 2013), (Mwangi, Otuya, and Kamau 2014), (Yassin et al. 2013). As a result, the findings are confirmed with some of the theoretical and experimental studies in the field of financial management practice on financial performance.

This study initiates some evidence of a direct linear relationship between the effects of financial management practice on financial performance. Such findings epitomize maintenance all previous financial management researchers in the field which has forecasted a linear relationship between the impact of financial management practice on financial performance. This study also contributes to the literature review by expanding the knowledge of the connection between financial management and financial performance.

The researchers believe that this study contributes to the continuous debate on the qualified importance of financial management practices to achieve financial performance among service companies in the Mogadishu area.

Contemporary suggests that the capability of companies to improve working capital management, investment decision, and financial performance. Those activities had been done six service companies are differences industries with other companies. In the same way, the differences will be influenced on financial performance, that is recommended, and therefore that competitive advantage can be achieved for business goals.

\section{References}

Addo, Isaac Kwame. 2017. "The Effect of Financial Management Practices on the Financial Performance of Top 100 Small and Medium Enterprises in Kenya.” 2912155 (1): 6-32.

Ali, Ali Yassin Sheikh, and Abdel Hafiez Ali. 2014. "Entrepreneurial Orientation and Performance of Women Owned and Managed Micro and Small Enterprises in Somalia." ZENITH International Journal of Multidisciplinary Research 4(1): 25-36.

Babin, Barry J, and Rolph E Anderson. On Multivariate Data Analysis Joseph F. Hair Jr. William C. Black Seventh Edition.

Based, America et al. 2016. "Effect of Internal Corporate Social Responsibility on Firm Financial Performance: Evidence from Kenya Commercial Bank." (11): 1-9.

Chen, Li-ju, Chang Jung, and Shun-Yu Chen. 2011. "How the Pecking-Order Theory Explain Capital Structure." Journal of International Management Studies 6.2 (1984): 1-9.

DEMBA, GOLDA AKINYI. 2013. "Effects of Financial Management Practices on Performance of Kenya Medical Training College.": 60.

Kabethi, Lucy. 2013. "The Effect of Working Capital Management Practices on the Financial Performance of Small and Medium Enterprises in Kenya." Journal of Business and Management 2 (3): 35-40. 
Kiprotich, Gideon. 2013. "Working Capital Management Practices and Financial Performance of Sugar Cane Outgrower Companies in Kenya." Journal of Business and Management 2 (1): 35-42.

Kwaning, John, Mbroh Director, and Benjamin Assah. 2015. "Financial Records Keeping and Business Decision Making Practices By Small and Micro Enterprise Owners in Ghana -Evidence From the Central Region." International Journal of Economics, Commerce and Management United Kingdom III (8): 467-91. http://ijecm.co.uk/.

Mwangi, Joseph Kimani, Robert Otuya, and David K Kamau. 2014. "Effect of Financial Management Practices On Profitability Of Matatu Transport Industry In Kenya." Journal of Economics and Finance (IOSR-JEF) 5 (5): $90-100$

Njagi, Irene Kageni, and Samuel Kariuki. 2017. "Equity Financing and Financial Performance of Small and Medium Enterprises in Embu Town , Kenya." 2(3): 74-91.

Town, Busia et al. 2017. "Financial Management Practices and Firm Performance Among Micro and Small Enterprises In." 4 (2): 303-10.

Yassin, Ali, Sheikh Ali, Abdiaziz Abdi Ali, and Abdiqani Ali Adan. 2013. "Working Conditions and Employees' Productivity in Manufacturing Companies in Sub-Saharan African Context: Case of Somalia." Educational Research International Educational Research International Educational Research International Educational Research International ISSN-L 2 (2): 2307-3713. www.savap.org.pk\%5Cnwww.erint.savap.org.pk. 